\title{
Design and Performance Analysis of a PV Control Scheme to Improve LVRT of Hybrid Power System
}

\author{
S. M. Istiaque Mahmud, Mohammad Abdul Mannan and Md. Rifat Hazari
}

\begin{abstract}
Solar power stations worldwide have been rising every year as well as the usage of sustainable power has increased. The addition into the traditional electricity grid networks of renewable sources such as the photovoltaic (PV) system is an essential challenge, given its erratic power generation. The major issue is to detach PV from the faulty grid, which leads to fluctuation in the system's interconnected PV system and system-wide energy interruptions. The low voltage ride through (LVRT) enables the PV scheme should stay linked to the grid even under fault situations in short periods and must assist the grid return to regular situations according to the modern grid codes. Hence, this paper develops and analyzes five aspects of the control strategy to increase the PV station's LVRT capability. The in-depth simulation of the independent units of the grid-connected large-scale PV farm is accomplished using PSCAD/EMTDC to assess the feasibility of the suggested control tactic for the modified IEEE nine-bus system.
\end{abstract}

Keywords: hybrid power system, low voltage ride through (LVRT), PV station, three line-to-ground (3LG) fault.

\section{Introduction}

Renewable energy has grown over more than $30 \%$ a year in the latest decades most rapidly expanding sectors concerning coal and lignite energy growth. There is a dramatic rising interest in power production from renewable energy. It is primarily attributed to the climate issues contributed to global warming by contemporary fossil fuels.

Policymakers across the region raised their environmental goals, released resolutions on the "climate emergency," all of which were followed by implementation proposals and targets for clean energy generation [1].

The sustainable energy market has undergone record-high integrated capability rises, surpassing cumulative carbon fuels and nuclear energy implementations merged. Built capability for sustainable energy (mostly solar PV) increased in 2019 by upwards of $200 \mathrm{GW}$ [1]. It is more cost-effective to produce energy through wind and solar PV in several nations than to generate it from modern coal-fired power plants.

S. M. Istiaque Mahmud is a master's student of EEE department of American International University-Bangladesh, Dhaka-1229, Bangladesh. Email: istiaquem.eee@gmail.com

Mohammad Abdul Mannan is a Professor and Director of the Department of EEE, American International University-Bangladesh, 408/1, Kuratoli, Khilkhet, Dhaka-1229, Bangladesh. Email: mdmannan@aiub.edu

Md. Rifat Hazari is an Assistant Professor of the Department of EEE, American International University-Bangladesh, 408/1, Kuratoli, Khilkhet, Dhaka-1229, Bangladesh. Email: rifat@aiub.edu
Proportionally, installed capacity for renewable energy was adequate to supply by the end of 2019 an expected 27.3 percent of worldwide electricity production [1].

Apart from these developments, renewable energy has persisted to experience obstacles in gaining a greater portion of worldwide power generation, partially due to continuing carbon fuel capacity investments [1].

To achieve a pollution-free source of electricity, the PV generator capacity of $650 \mathrm{GW}$ installed by 2050 must be raised to over 4 TW by 2025 [2].

Such an immense PV system implementation in the power system has an important effect on system reliability. Medium voltage grid codes have been issued in recent decades by PV systems, providers demanding that these systems participate and play a major role in grid failure systems [3].

In order for these grid protocols to have complied with the PV system must meet the LVRT functionality condition and stay in the grid-connected state right after the interruption. LVRT standards have been applied globally to ensure that grids such as PV work smoothly. The PV will stay attached to the distribution network through a failure situation [4]. Furthermore, according to IEEE Standard 1547a [5], requires distributed energy resources (DERs) to stay connected to the grid over a much broader range of voltage levels for much longer periods of time, essentially enabling voltage ride through. In addition, IEEE 1547 a allows DERs to apply to grid voltage control. A complete revision of IEEE 1547 is currently ongoing to expand the incorporation of DERs, which would not only enable but also require DERs to ride through a variety of faults and assist with grid voltage control.

Numerous different supplementary techniques may be utilized to improve their LVRT capabilities under network failure situations, such as magnetic energy recovery switch [6], series dynamic braking resistor [7] and, bridge-type fault current limiter [8]. Consequently, the average expense of the module increases.

In this paper, five different types of control schemes are studied and compared to achieving the better performance of the PV system's power qualities under 3LG.

The paper is arranged as: the power system concept is introduced in Section II. The next segment is all about the proposed model of PV power plants and under this section design of the PV module as well as the proposed PV Power plant control strategy also explained. Section IV demonstrates the capability of LVRT. In section $\mathrm{V}$, the aforementioned five control strategies have been simulated by PSCAD/EMTDC, 
and also the effectiveness of those control strategies on voltage under 3LG are compared. Finally, the paper concludes with a brief overview in the last segment.

\section{Model of Power System}

The power system principle employs in this paper is demonstrated in Fig. 1. The main system with a 9bus and a PV plant consists of this model. There are two thermals as well as a hydraulic power plant named SG1, SG2, and SG3, respectively. Automatic generation control (AGC) is used by SG1 and SG3. SG2 is managed by governor-free (GF) control. On bus 5, a PV plant is connected with a central grid.

The capacity of the PV plant is $20 \mathrm{MW}$. Fig. 2 displays the PV system. The PV plant is connected by $0.69 \mathrm{kV} / 66 \mathrm{kV}$, transformer $66 \mathrm{kV} / 230 \mathrm{kV}$ double circuit transmission line in bus 5. For all SGs, the IEEE style AC4A solid-state exciter is defined as being an exciter scheme, as seen in Fig. 3 [9]. The AC4A exciter parameters are represented in Appendix.

The governor system model is used for both hydroelectric power and thermal power units described in Ref. [9]. The reheat-based steam turbine controllers in thermal power generators are known as SG1 and SG2 seen in Fig. 4 [9].

Fig. 5 displays the hydro turbine governor scheme schedule which consists of a transient droop compensator system [9].

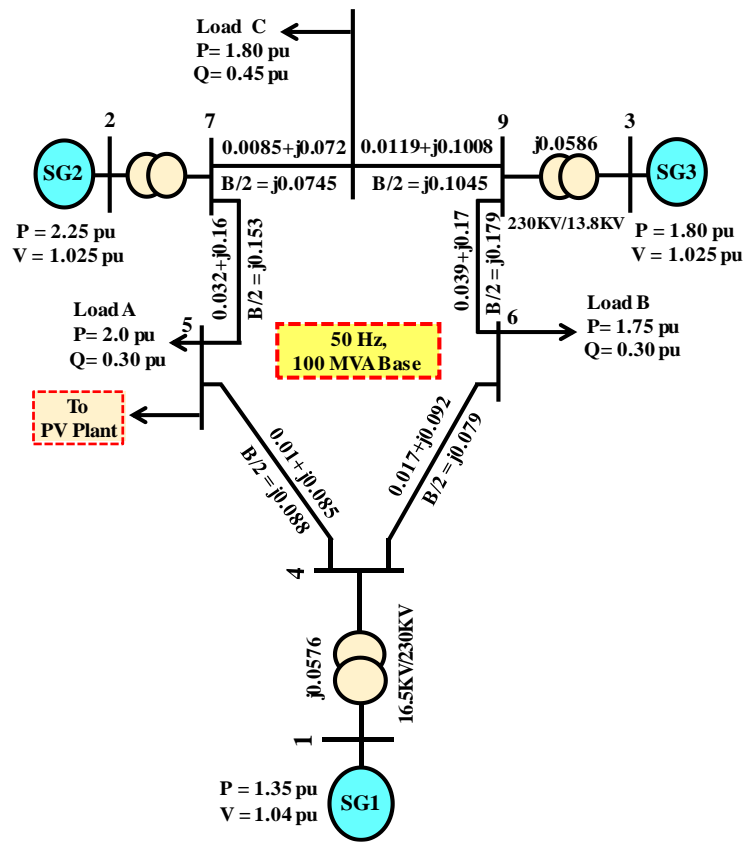

Fig. 1: Model of power system.

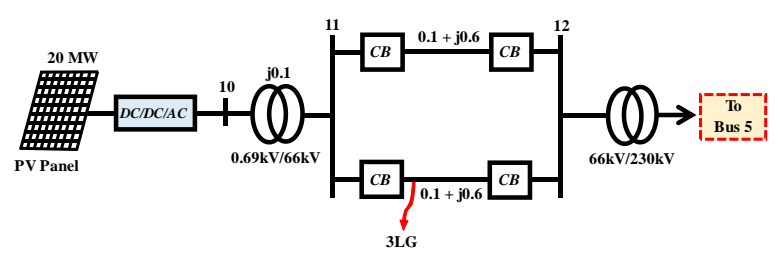

Fig. 2: Layout of PV farm.

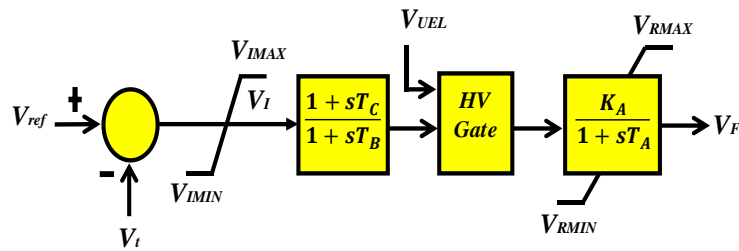

Fig. 3: AC4A exciter scheme.

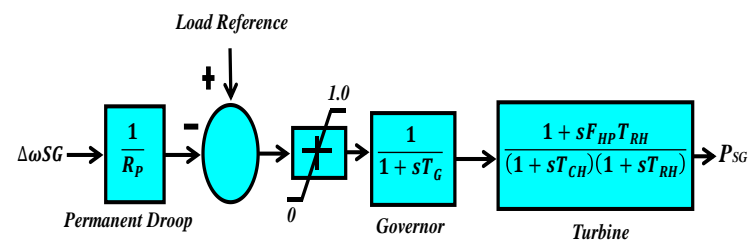

Fig. 4: Model of thermal governor.

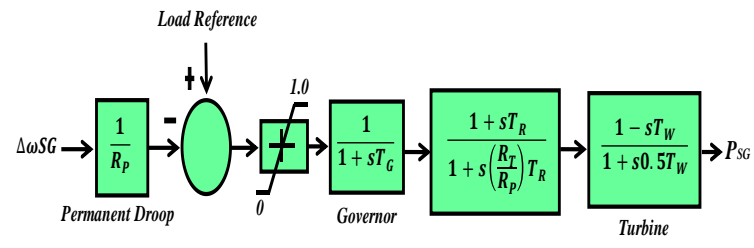

Fig. 5: Model of hydro turbine governor.

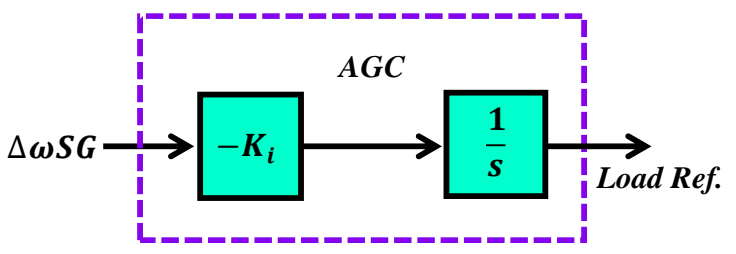

Fig. 6: Integral controller for AGC.

The AGC framework provides an automated control system for SG1 and SG3. The integrated AGC operation controller appears in Fig. 6. The integral gain for $K_{i}$ is set at 6 .

\section{Model of PV Power Plant}

\subsection{Design of PV Module}

Fig. 7 indicates an equivalent circuit of the PV concept. A single diode model, fast, simple, and reliable, is used for this research [10]. The single diode PV model can be represented by a current source, series, and parallel resistor and diode.

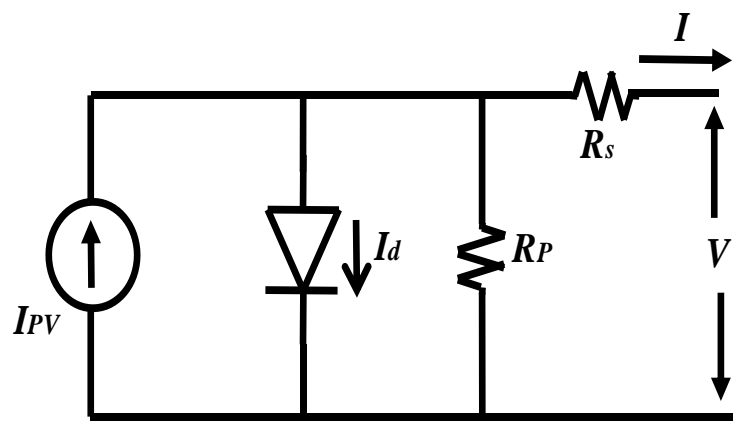

Fig. 7: Single diode PV equivalent circuit. 
This is the unified design of a PV farm made up of several PV modules. [10, 11, 12]:

$I=N_{P} I_{P V}-N_{P} I_{o}\left[\exp \left(\frac{\left(V+R_{s}\left(\frac{N_{M}}{N_{P}}\right) I\right.}{N_{M} a V_{t}}\right)-1\right]-\frac{V+R_{s}\left(\frac{N_{M}}{N_{P}}\right) I}{R_{p}\left(\frac{N_{M}}{N_{P}}\right)}$

Here, $N_{M}=$ number of series-connected modules in a string and $N_{P}=$ number of parallel-connected modules in a string. Fig. 8 indicates that the characteristics curves ( $I$ vs $V$ and $P$ vs $V$ ) of $20 \mathrm{MW}$ PV farm. All data for such a $20 \mathrm{MW}$ PV farm is seen in Appendix.

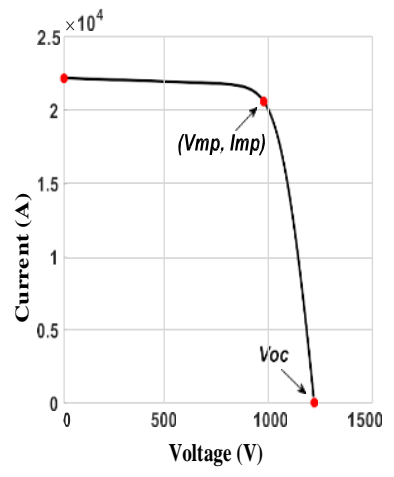

(a) $I$ vs $V$

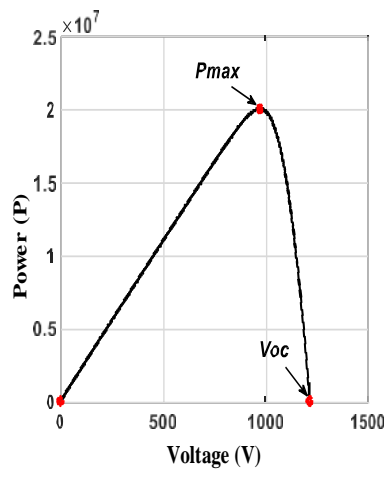

(b) $P$ vs $V$
Fig. 8: Characteristics of 20 MW PV Farm.

\subsection{PV Plant Control Mechanism}

The PV system and its control mechanism are demonstrated in Fig. 9. A PV module, a DC-DC stepup converter and a power inverter make up the unit. The DC-DC converter and the control system of the power inverter control the $\mathrm{DC} / \mathrm{DC}$ converter and the $\mathrm{DC} / \mathrm{AC}$ inverter at the same time.

The insulated gate bipolar transistor (IGBT) is used to build both converters and inverters. In addition, the pulse width modulation (PWM) approach has been used for each converter.

The DC distribution model is concentrated on Ref. [13] as well as the specifications for the $1 \mathrm{X} 300 \mathrm{~mm}^{2}$ TOP SOLAR XZ-K cable [14] are employed.

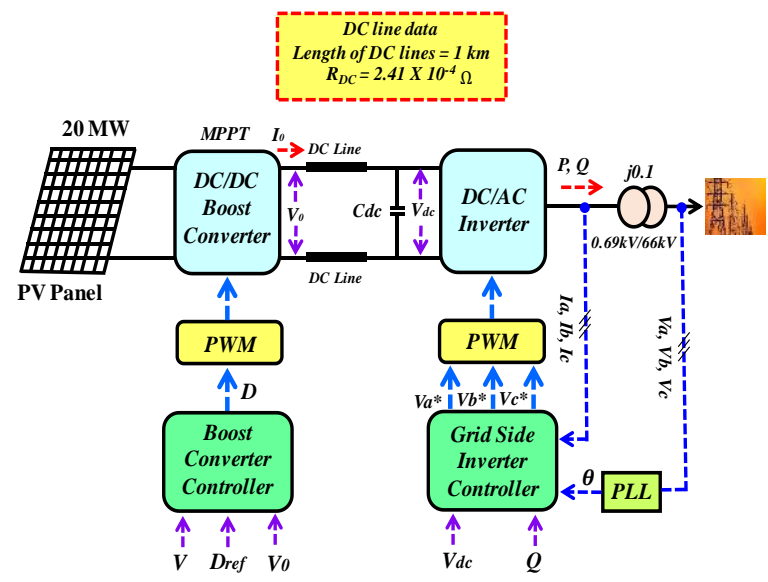

Fig. 9: PV plant control strategy.
In the PV power plant, a step-up converter has been used to maximize the output voltage amount and pull from the PV plant the maximum power point tracking (MPPT) power. It is achieved by changing the output voltage of the PV plant for appropriate irradiation and temperature to a particular value.

The technique of fractional $V_{o c}$ was utilized in this research to achieve maximum power output [11].

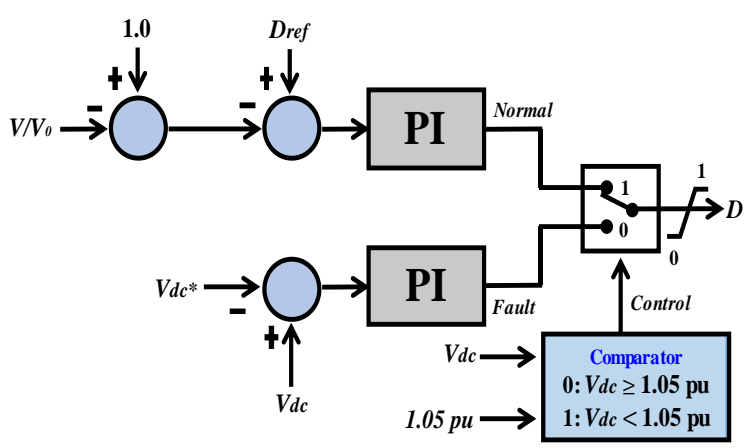

Fig. 10: Control system of DC-DC step-up converter.

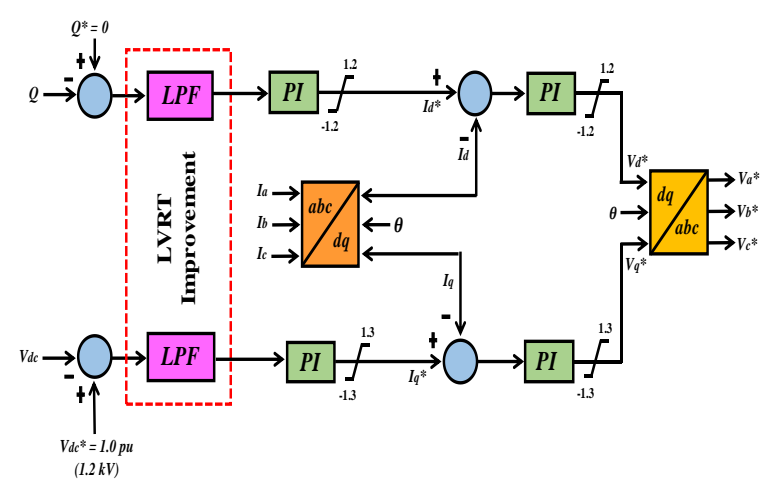

Fig. 11: Proposed control system of GSI with LPF.

The controller of the DC-DC boost converter is shown in Fig. 10. Owing to a sudden drop in terminal voltage due to network loss on the grid side, the $V_{d c}$ is much higher. For that purpose, the PV panel's incoming power cannot be passed to the delivery grid.

In the DC-DC converter control system, an external control technique is then added, as seen in Fig. 10. The MPPT power controller is overridden, and the lower PI controller can make up for the $V_{d c}$ error signal. $V_{d c}$ persists in an equitable range due to these expanded methods of control methodology.

The proposed grid side inverter (GSI) control system is represented in Fig. 11 and this control system includes four mainstream PI controllers. The power inverter control system controls the reactive power supplied to the distribution network and keeps the $V_{d c}$ constant such that it is possible to pass the active power to the grid. By setting the reactive power reference to 0 , the function of the unity power factor is guaranteed. The comparator sends out a signal such that the successful power transfer to the distribution network is 0 in a fault condition, where the grid side voltage is less than $0.9 \mathrm{pu}$. 
In this case, the low-pass filter (LPF) is employed to assess the system performance of the conventional control system of the inverter (without any comparator). The implementation of a low-pass filter introduces itself as a possible solution to this PV system to achieve more reliable and stable performance.

\section{LVRT Capability Requirement}

Fig. 12. demonstrates the requirement of LVRT for PV farms [4]. When the voltage drop is in the specified root mean square value, the PV farms must stay linked with the power network, furthermore, the specified timeframe has shown in Fig. 12.

The PV plants shall remain to stay connected without tripping when the voltage of the connecting position restores to $90 \%$ of the rated voltage in $1.5 \mathrm{~s}$ thereafter the incidence of a voltage drops.

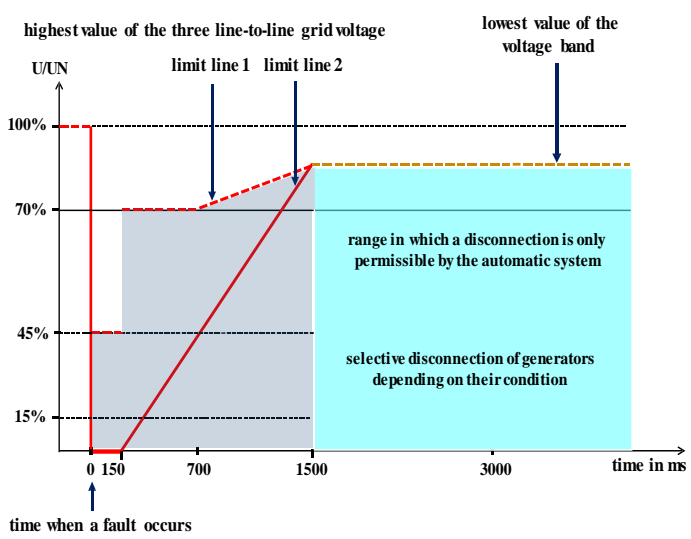

Fig. 12: Requirement of LVRT

\section{Simulation Results and Case Study}

For the purpose of investigating the simulation, the diagram of the power system in Fig. 1 is used. The rated frequency is assumed to be $50 \mathrm{~Hz}$. For adequate performance, the simulation time is set to $10 \mathrm{~s}$, the time step is $5.0 \mu \mathrm{s}$ and the channel plot step is $5000 \mu \mathrm{s}$. 3LG is viewed as a system interruption.

As seen in Fig. 2, the fault occurs at $0.1 \mathrm{~s}$ on the transmission line near bus 11 . The time for faults is 5 cycles $(0.1 \mathrm{~s})$. At $0.2 \mathrm{~s}$, the circuit breakers $(\mathrm{CBs})$ are opened on the faulty line to disentangle the faulty line from the power network. The irradiance including the cell temperature is preserved stable.

In order to choose the most feasible PV plant control scheme to boost LVRT capacity and transient stabilities, five separate case studies are carried out. The case studies are mentioned below-

Case 1: No DC-Link protection scheme is used in the DC-DC converter (no comparator) demonstrated in Fig. 10 and normal grid side inverter (GSI) controller (without comparator and low pass filter) presented in Appendix (Fig. A1).

Case 2: Using the step-up (DC/DC) converter control scheme depicts in Fig. 10 and GSI controller (without using low pass filter) depicts in Appendix (Fig. A2).

Case 3: Using the step-up (DC/DC) converter control system demonstrated in Fig. 10 (without using DC-
Link protection system) and GSI controller (without any low pass filter) presented in Appendix (Fig. A2).

Case 4: Using the step-up (DC/DC) converter controller represented in Fig. 10 and normal GSI (without using a comparator and low pass filter) grid side inverter controller illustrated in Appendix (Fig. A1).

Case 5: Using the DC-DC converter control system presented in Fig. 10 and normal grid side inverter controller with low pass filter (LPF) represented in Fig. 11.

The output voltage of the PV plant for the five different cases is illustrated in Fig. 13, in which it is noticeable that case 5 has high efficiency in all cases. Furthermore, case 5 indicates the lowest voltage dip after even a 3LG fault. This is achieved by supplying an adequate and efficient amount of reactive power throughout the transient state in case 5 contrasted with cases 1, 2, 3 and 4 as seen in Fig. 14. Whereas, in cases 1, 2 and 3, the PV inverter supplies a very limited amount of reactive power throughout a 3LG fault. Consequently, the terminal voltage of the PV plant fails to easily return to its usual state. In comparison, the voltage response of cases 1,2 and 3 fluctuates tremendously in the steady-state as well as in the transient state.

The active power feedback for the PV farm is shown in Fig. 15. Case 5, of all cases, seems to be a stable response. In case 2, some large variations in the steady-state and transient state can be observed. Furthermore, the DC link voltage has come back to a normal state so quickly after the fault condition in Case 5 compared to all other cases as presented in Fig. 16. In cases 1 and 3, the voltage of the DC-Link increases dramatically. Since in the DC-DC converter controller no protection mechanism is used.

The active power variations of SGs are greater after 3LG fault in cases 1, 2, 3 and 4 compared to case 5 as observed in Fig. 17.

As a consequence, in those cases rotor speed is gradually dropped therefore the rotor speed of SGs in case 5 is more stable as compared to other cases, shown in Fig. 18. The power angel of SGs is illustrated in Fig. 19. The output curve indicates that the system is stable in case 5 but, in other cases, the system is not able to sustain stability due to the event of a 3LG fault.

The following basis of this simulation analysis, case 5 gives the optimal result among all the cases.

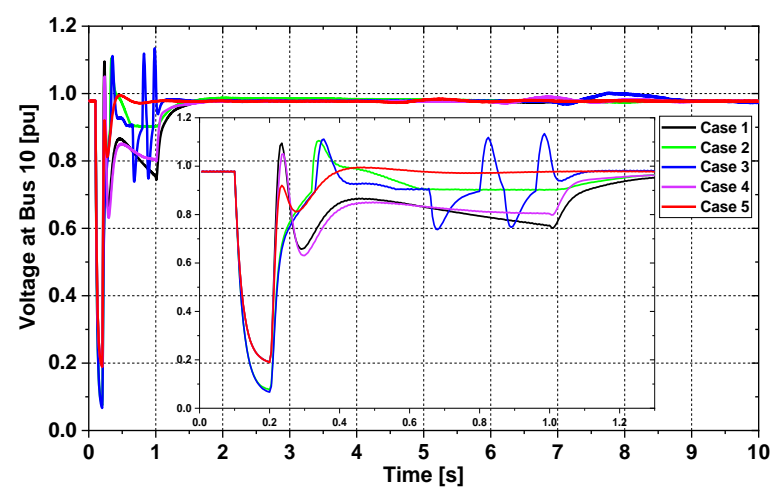

Fig. 13: Voltage feedback at PV side (Bus 10). 


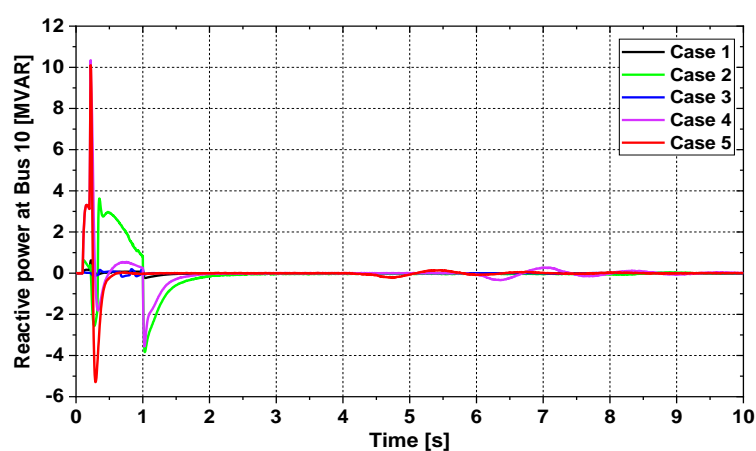

Fig. 14: Reactive power of PV farm (Bus 10).

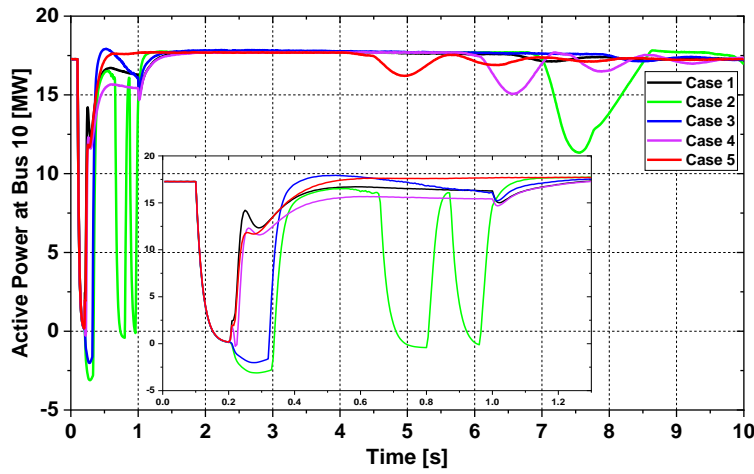

Fig. 15: Active power of PV farm (Bus 10).

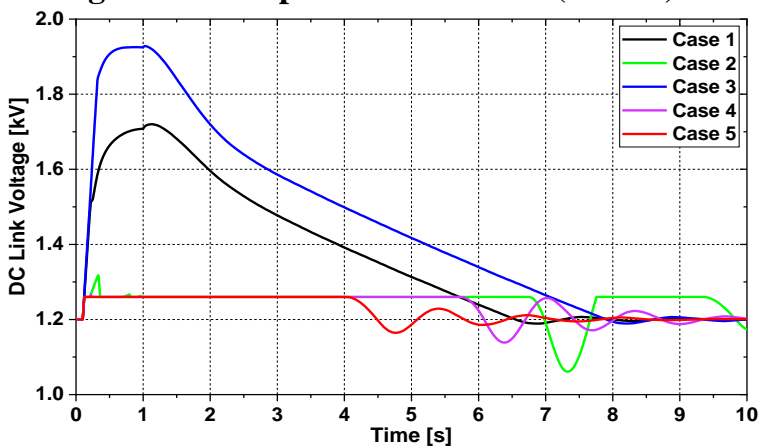

Fig. 16: DC-Link voltage feedback of PV farm.

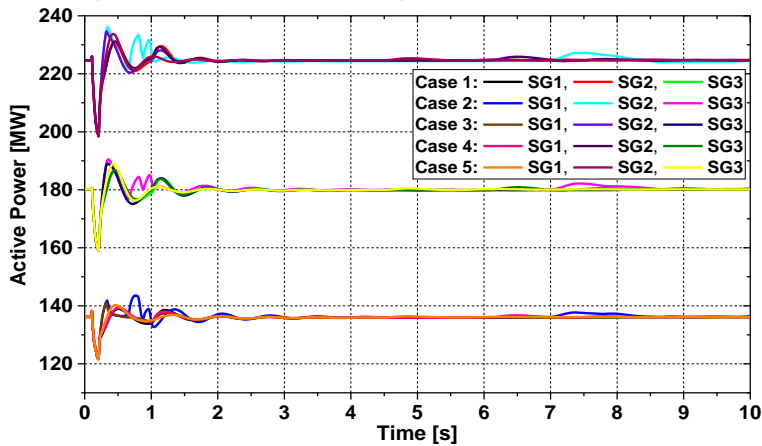

Fig. 17: The feedback of active power of SGs.

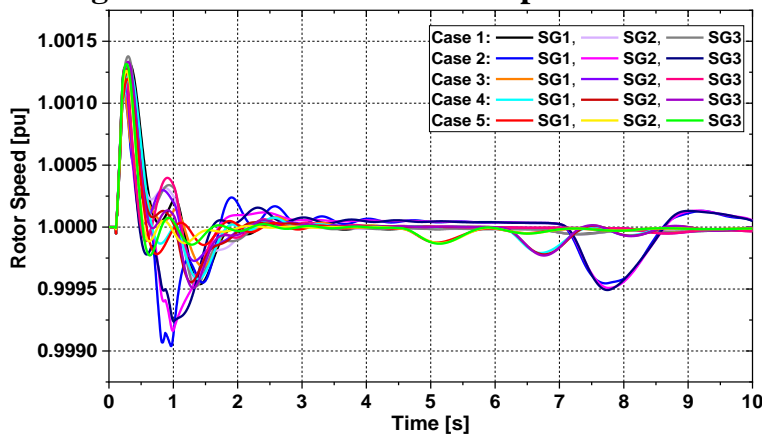

Fig. 18: Rotor speed feedback of SGs.

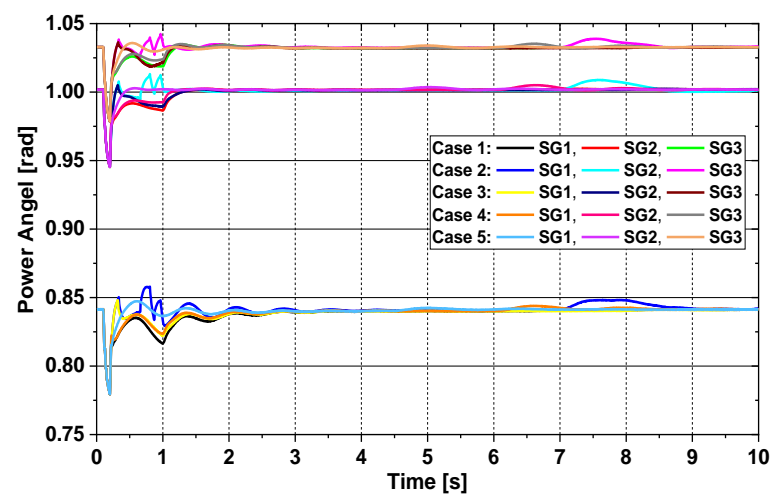

Fig. 19: Power angel feedback of SGs.

\section{Conclusions}

Five various types of control techniques are being studied in this research to strengthen LVRT capabilities in a grid-connected PV system consisting of a main 9bus system with three traditional power plants. The best performance is obtained by inserting the reactive power into the grid throughout the fault state by regulating the PV GSI mechanism. The results show that, among all case studies, the use of the step-up DC-DC converter with DC Link protection scheme and normal GSI with low pass filter (LPF) controller is very effective to strengthen the ability of complete PV system stability under transient conditions. Hence, the hybrid power system including conventional power stations and PVs system is more stable with an improved LVRT capability.

\section{References}

[1] Renewables 2020 Global Status Report; REN21. 2020 (Paris: REN21 Secretariat). ISBN 978-3-948393-00-7.

[2] Jäger-Waldau, A., PV Status Report 2019, EUR 29938 EN, Publications Office of the European Union, Luxembourg, 2019, ISBN 978-92-76-12608-9, doi:10.2760/326629, JRC118058.

[3] G. J. Kish, "Addressing future grid requirements for distributed energy resources," M.Sc. thesis, Dept. Elect. Comput. Eng., Univ. Toronto, Toronto, ON, Canada, 2011.

[4] E. ON NETZ GmbH (2006) Grid Connection Regulation for High and Extra High Voltage. E. ON NETZ GmbH, Essen, Germany.

[5] IEEE Draft Standard for Interconnecting Distributed Resources with Electric Power Systems -Amendment 1, IEEE Standard P1547a, 2013.

[6] Wei, Y.; Kang, L.; Qi, R.; Wen, M.; Cheng, M.M. Optimal control of SVC-MERS and application in SCIG powered micro-grid. In Proceedings of the 2014 IEEE Applied Power Electronics Conference and Exposition-APEC 2014, Fort Worth, TX, USA, 16-20 March 2014; pp. 3367-3373.

[7] Gatavi, E.; Hellany, A.; Nagrial, M.; Rizk, J. Improved Low Voltage Ride-Through capability of DFIG-based wind turbine with breaking resistor and converter control. In Proceedings of the 2018 IEEE 12th International Conference on Compatibility, Power Electronics and Power Engineering (CPE-POWERENG 2018), Doha, Qatar, 10-12 April 2018; pp. 1-6.

[8] Marei, M.I.; El-Goharey, H.S.K.; Toukhy, R.M. Fault ride-through enhancement of fixed speed wind turbine using bridge-type fault current limiter. J. Electr. Syst. Inf. Technol. 2016, 3, 119-126. 
[9] P. Kundur, "Power System Stability \& Control," McGraw-Hill Inc.

[10] H. M. Hasanien, "An Adaptive Control Strategy for Low Voltage Ride Through Capability Enhancement of GridConnected Photovoltaic Power Plants," in IEEE Transactions on Power Systems, vol. 31, no. 4, pp. 32303237, July 2016.

[11] G. M. S. Islam, A. Al-Durra, S. M. Muyeen and J. Tamura, "A robust control scheme to enhance the stability of a grid-connected large scale photovoltaic system," PES T\&D 2012, Orlando, FL, 2012, pp. 1-6.

[12] M. K. Hossain and M. H. Ali, "Low voltage ride through capability enhancement of grid connected PV system by SDBR," in Proc. IEEE PES T\&D Conf. Expo., 2014, pp. 1-5. [13] M. R. Starke, "DC distribution with fuel cells as distributed energy resources," Ph.D. dissertation, Dept. Electric. Eng., Univ. Tennessee, Knoxville, 2009.

[14] Cables for photovoltaic solar installations. [Online]. Available:www.elesis.gr/php/download.php?file=solar_cabl es_presentation.pdf

\section{Appendix}

Table A1: IEEE Type AC4A Exciter Values.

\begin{tabular}{|c|c|c|c|}
\hline \multicolumn{2}{|c|}{ Steam Turbine } & \multicolumn{2}{c|}{ Hydropower Turbine } \\
\hline Parameter & Value & Parameter & Value \\
\hline$R_{P}$ & 0.06 & $R_{P}$ & 0.06 \\
\hline$T_{G}$ & $0.3 \mathrm{sec}$ & $T_{G}$ & $0.3 \mathrm{sec}$ \\
\hline$T_{C H}$ & $0.2 \mathrm{sec}$ & $R_{T}$ & $0.35 \mathrm{sec}$ \\
\hline$T_{R H}$ & $8.0 \mathrm{sec}$ & $T_{R}$ & $6.0 \mathrm{sec}$ \\
\hline$F_{H P}$ & 0.4 & $T_{W}$ & $2.0 \mathrm{sec}$ \\
\hline
\end{tabular}

Table A2: A 20 MW PV Farm Specifications.

\begin{tabular}{|c|c|}
\hline$P_{\max }$ & $20 \mathrm{MW}$ \\
\hline$V_{m p}$ & $973.1 \mathrm{~V}$ \\
\hline$I_{m p}$ & $20580 \mathrm{~A}$ \\
\hline$N_{m}$ & 37 \\
\hline$N_{P}$ & 2704 \\
\hline
\end{tabular}

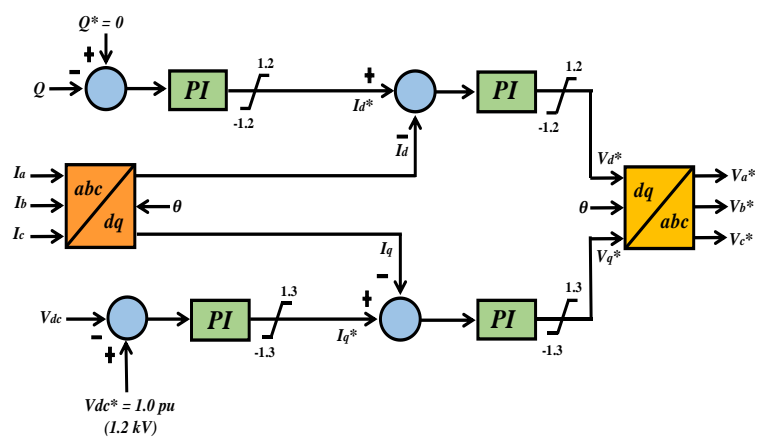

Fig. A1: Conventional GSI controller with reactive power as feedback.

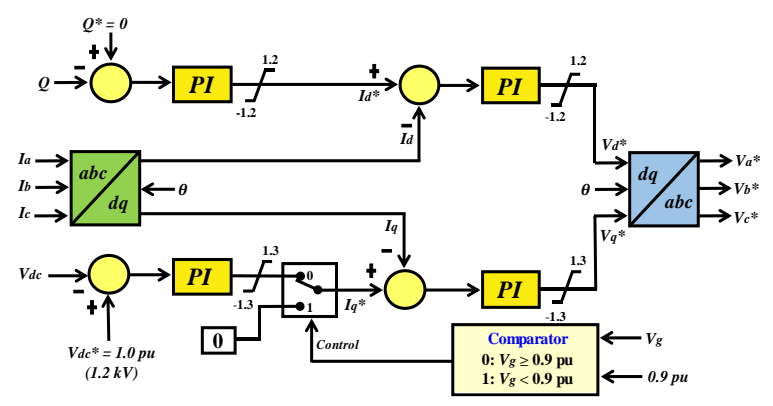

Fig. A2: Conventional control system of GSI with terminal voltage as feedback.

S. M. Istiaque Mahmud received his B.Sc. Engg. Degree in

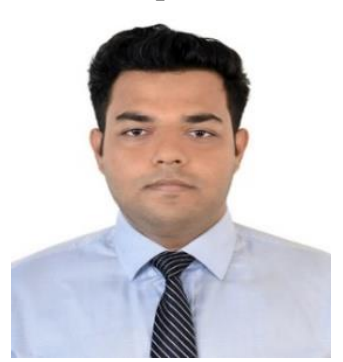
Electrical and Electronic Engineering from American International UniversityBangladesh (AIUB) in December 2018. Currently, he is completing his M.Sc. Engg. Degree in Electrical and Electronic Engineering from American International UniversityBangladesh (AIUB). His research interests are Renewable energy systems (photovoltaic power $\&$ wind power systems in particular), power electronics, power system stability \& control, and hybrid power systems.

Mohammad Abdul Mannan was born in Laxmipur,

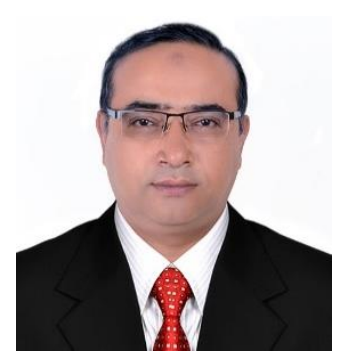
Bangladesh on January 01, 1975. He received his B. Sc. Eng. Degree from Rajshahi University of Engineering and Technology (RUET former BITR), Bangladesh, in 1998, and Masters of Eng. and Dr. of Eng. degrees from Kitami Institute of Technology, Japan, in 2003 and 2006 respectively, all in electrical engineering. He then joined in the American International University Bangladesh (AIUB) as an Assistant professor in May 2006. He served in AIUB as an Associate Professor from December 2013 to November 2016. Now he is working as a Professor and Director of Faculty of Engineering in AIUB. His research interests include electric motor drive, power electronics, power system, wind generation system and control of electric motor, power electronic converters, power system, and wind generation system. Prof. Dr. Mannan is a member of the IEB and IEEE.

Md. Rifat Hazari received his B.Sc. Engg. and M.Sc. Engg.

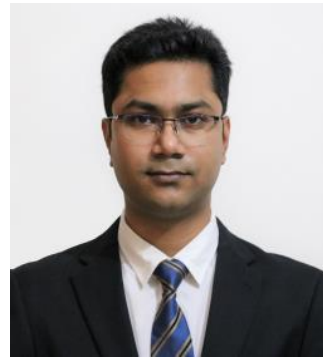
Degrees in Electrical and Electronic Engineering from American International University-Bangladesh (AIUB) in August 2013 and December 2014, respectively and Ph.D. Degree in Energy Engineering from Kitami Institute of Technology (KIT), Japan, in March 2019. He served as a Lecturer in Electrical and Electronic Engineering department 
at AIUB. Currently, he is working as an Assistant Professor in the Electrical and Electronic Engineering department at AIUB. He received the MINT (Academic Excellence) Award 2017 from KIT for the outstanding research of 2017 academic year, Best Paper Award in the Australasian Universities Power Engineering Conference 2017, Melbourne, Victoria, Australia and Best Presentation Award in the IEEJ Branch Convention 2017, Hakodate, Japan. His research interests are renewable energy systems (especially wind power \& photovoltaic power systems), power system stability and control, microgrid and hybrid power systems, HVDC system, analysis and control of rotating electrical machines. Dr. Hazari is a member of IEEE. 